\title{
Participação dos beneficiários em estratégias de redução da pobreza: análise de suas contribuições
}

\section{Introdução}

Pobreza é um fenômeno multidimensional e suas causas são complexas. Ela pode ser entendida, grosso modo, como padrão de vida abaixo do que é socialmente aceitável. É mais que insuficiência de renda ou consumo; inclui, também, vulnerabilidade, insegurança, isolamento, exclusão e falta de poder ${ }^{1}$. Atualmente, 2,8 bilhões de pessoas - quase metade da população mundial - vive com menos que US $\$ 2,00$ por dia e 1,2 bilhão um quinto - vive com menos que US\$1,00 por dia, sendo consideradas pobres para fins de estatísticas internacionais de comparação (The World Bank, 2001). No Brasil, são 53,1 milhões de pessoas abaixo da linha de pobreza (Barros et al., 2001).

Um importante elemento da discussão atual de como combater a pobreza é o envolvimento dos stakeholders primários ${ }^{2}$ nas atividades da intervenção de desenvolvimento ${ }^{3}$ (Bhatnagar e Williams, 1992; Chambers, 1993; Nelson e Wright, 1995; Karl, 2000). Acredita-se que existe relação direta entre uma ativa participação dos beneficiários e o sucesso do programa/projeto (Oakley, 1991). Conseqüentemente, um considerável número de agências de desenvolvimento está adotando enfoques participativos em suas operações. No caso do Brasil, podemos citar, por exemplo, os programas governamentais "Comunidade Ativa" "Fome Zero" e "Programa Nacional de Fortalecimento da Agricultura Familiar (Pronaf)" que utilizam instituições locais, formadas por membros da comunidade, para implementar as suas ações.

Dada a sua ampla utilização, o termo "participação" tem apresentado diversos sentidos e tem sido usado para diferentes propósitos. Algumas

Willber da Rocha Severo é Especialista em Políticas

Públicas e

Gestão

Governamental e CoordenadorGeral de

Parcerias

Empresariais do Ministério do

Trabalho e

Emprego.

Contato:

willber.severo

@ mte.gov.br 
pessoas vêem "participação" como forma de fazer os programas/projetos mais sensíveis às necessidades dos pobres. Outros entendem que a "participação" dos despossuídos facilita uma mudança política em seu favor (Blackburn e Holland, 1998). Alguns consideram-na "meio" usado para atingir certos objetivos predeterminados ou como "fim" - participação como processo de fortalecer as capacidades ${ }^{4}$ das pessoas de maneira a permiti-las ter controle sobre o seu próprio desenvolvimento (Nelson e Wright, 1995) $)^{5}$. A rápida expansão de métodos e técnicas participativas em anos recentes reflete esta riqueza ${ }^{6}$.

Essa multiplicidade de conceitos e objetivos é tão reconhecida que vários estudiosos têm desenvolvido sistemas classificatórios para a participação. Os termos "tipos", "dimensões", "níveis", "graus", entre outros, usados nessas classificações identificam basicamente: (1) em que fase do ciclo da política/programa/projeto a participação dos beneficiários ocorre: na formulação, na implementação, no monitoramento ou na avaliação; (2) a qualidade, intensidade ou extensão da participação: como beneficiário passivo, como consultor, como tomador de decisão ou controlador, etc.; e (3) a abrangência territorial da participação: local, regional ou nacional (Rudqvist e Woodford-Berger, 1996).

Independentemente desses diferentes entendimentos e propósitos, existe grande expectativa sobre as contribuições positivas da participação dos beneficiários na redução da pobreza ${ }^{7}$. A hipótese assumida é que essa participação melhora a qualidade e aumenta a efetividade, a eficiência e a sustentabilidade das intervenções desenvolvimentistas. Ela beneficiaria o pobre, incrementando suas capacidades e levando ao seu empoderamento. Infelizmente, experiências em avaliá-la são ainda limitadas (Karl, 2000; Rudqvist e Woodford-Berger, 1996; Oakley et al., 1998), especialmente no Brasil. A atenção tem sido mais focada em identificar os stakeholders e medir a extensão e qualidade de sua participação do que mensurar os seus impactos (Karl, 2000). Ademais, existe uma lacuna de informações sobre em que contexto e circunstâncias as contribuições podem materializar-se. Algumas questões permanecem sem respostas satisfatórias. Particularmente, como e em que extensão a participação dos beneficiários aumenta a efetividade, a eficiência e a sustentabilidade das intervenções desenvolvimentistas? Como e em que extensão ela empodera os stakeholders primários? Quais são os desafios e dificuldades para implementar estratégias participativas?

Dessa forma, os objetivos deste trabalho são: (1) examinar e sintetizar a literatura sobre participação, de maneira a responder essas questões, e (2), a partir desta revisão, emitir recomendações para serem adotadas em futuras políticas de combate à pobreza. Ele está dividido em quatro seções. A primeira apresenta uma introdução geral sobre o tema, destacando a importância da participação como componente das estratégias 
de redução da pobreza, seus diferentes entendimentos e objetivos. A seção

2, a partir das evidências da literatura especializada, analisa as contribuições da participação em termos de empoderamento dos beneficiários e melhorias na efetividade, eficiência e sustentabilidade das intervenções desenvolvimentistas. A seguir, são identificados os desafios e as dificuldades para garantir uma real participação. Finalmente, a seção 4 revê as principais conclusões do estudo e faz algumas recomendações.

\section{Contribuições da participação}

A literatura foi consultada de maneira a permitir análise das contribuições da participação para a redução da pobreza. Os textos foram revistos em termos de empoderamento, efetividade, eficiência e sustentabilidade. Esses critérios foram formulados em consideração às questões conceituais apresentadas na Introdução.

\section{Empoderamento dos beneficiários}

Empoderamento, como participação, é um termo complexo que não é facilmente definido e tem diversas interpretações ${ }^{8}$. Ele é focado nas noções de "poder" - seu uso e distribuição - (Oakley e Clayton, 2000) e de "construção de capacidade" (Narayan, 1995).

Pobreza significa, freqüentemente, ausência de poder e exclusão social, resultantes da discriminação, do isolamento e da falta de direitos humanos (Chambers, 1983). Empoderamento é, desta forma, crucial para sua redução. Ele permite que os pobres influenciem nas decisões que afetam as suas vidas e tenham acesso a recursos produtivos.

Os casos apresentados a seguir mostram como o envolvimento dos beneficiários nas atividades das intervenções desenvolvimentistas pode aumentar o seu senso de controle sobre suas vidas, quebrar a sua mentalidade de dependência, construir suas capacidades e fortalecer sua voz, entre outros efeitos positivos.

Como resultado da participação no "People's Participation Programme" (PPP) em Gana (Bortei-Doku, 1991), foi identificado que as organizações participativas locais representavam os interesses dos pobres rurais e serviam como base para um crescente envolvimento dos beneficiários nas atividades do Programa. PPP fez os serviços financeiros públicos (empréstimos e poupança) ficarem disponíveis para pequenos agricultores, que eram anteriormente excluídos.

Semelhantemente, Hinchliffe et al. (citado por Karl, 2000), em estudo sobre os impactos sociais, econômicos e ambientais de projetos de irrigação, identificaram que os maiores benefícios da participação dos 
stakeholders primários foram o aumento da confiança e do senso de coesão das comunidades, a redução das emigrações, maior atenção às necessidades dos grupos sem-terra e o estabelecimento de uma nova relação de apoio entre as pessoas e os profissionais das agências de desenvolvimento.

Em estudo comparativo de três países (Bolívia, Burkina Faso e Indonésia), Grootaert (2001) descobriu que bons níveis de capital social reduzem significativamente a probabilidade de uma pessoa ser pobre. Famílias bem dotadas deste capital eram mais hábeis na acumulação de ativos e na obtenção de crédito, o que lhes ajudava a lidar melhor com o risco de flutuações negativas de renda. Neste caso, a ativa participação dos membros das famílias no processo de decisão das organizações locais contribuía para construir capital social.

Da mesma forma, Coirolo e Barbosa (2002), analisando a experiência dos "Projetos de Alívio da Pobreza Rural" (PAPR) financiados pelo Banco Mundial no Nordeste brasileiro, encontraram que o capital social desenvolvido durante o processo geral de participação permitiu aos beneficiários conseguirem outras fontes de financiamento que antes eles não tinham acesso e os ajudou a vender seus produtos para os mercados internacionais.

Esses estudos confirmam a influência positiva da participação em promover confiança, em fortalecer a voz dos excluídos, em melhorar a capacidade local para resolver problemas e em gerar capital social. No entanto, a extensão em que isto ocorre depende do tipo de participação. Com o baixo envolvimento dos stakeholders primários na implementação do "Water Supply Project" (WSP) na Tanzânia (Therkildsen, 1991), conseguiu-se, apenas, obter contribuições em forma de trabalho voluntário, apesar dos esforços para mobilizar e empoderar as pessoas, para que estas tivessem papel ativo em todas as fases do projeto. Da mesma forma, a capacidade operacional das associações de agricultores era pequena na primeira fase de implementação do "Self-Help Support Programme" (SSP) no Sri Lanka (Samaranayake, 1998) devido a não-participação dos beneficiários no processo de escolha das estruturas físicas que seriam construídas.

Por outro lado, um estudo de caso do "World Bank Community Driven Development" (The World Bank, 2002b) mostra como a um alto nível de participação empodera os beneficiários. O Programa "Mvula Trust" provê água potável e saneamento básico em áreas rurais da África do Sul. Os membros da comunidade são envolvidos de diferentes formas: $8 \%$ dos custos de construção da infra-estrutura física dos projetos são pagos em dinheiro pelos próprios usuários; eles são responsáveis pelo gerenciamento dos recursos financeiros do Programa; eles mantêm contatos diretos com os engenheiros e profissionais nas fases de formulação e implementação dos projetos; e, finalmente, a operação e manutenção 
dos projetos são de inteira responsabilidade da comunidade. Como conse-

qüência desse enfoque fortemente participativo, o Programa contribuiu para a auto-organização de instituições locais e motivou o desenvolvimento de agências governamentais mais efetivas e pró-pobres, o que influenciou a administração sul-africana a adotar iniciativas similares em outras áreas.

Resultados semelhantes foram alcançados no âmbito dos PAPR. A sua estratégia altamente participativa e empoderadora permitiu que as comunidades mais pobres recebessem financiamento para implementar, operar, administrar e manter subprojetos de investimento da sua escolha e contratar diretamente assistência técnica.

\section{Efetividade das estratégias}

Efetividade pode ser entendida como a extensão em que uma intervenção atinge seus objetivos. Um programa/projeto pode prover um produto ou serviço, mas não necessariamente causar efeito ${ }^{9}$ sobre o seu público-alvo.

De acordo com a teoria, uma das mais importantes contribuições da participação dos stakeholders primários é aumentar a efetividade das intervenções desenvolvimentistas. De fato, um dos motivos para muitos programas/projetos não terem tido êxito é a ausência de envolvimento dos seus beneficiários. Acredita-se que as intervenções têm maior chance de atingir seus objetivos se eles forem identificados e avaliados com a participação das pessoas diretamente afetadas (Karl, 2000). Adicionalmente, se os beneficiários participarem ativamente da formulação e implementação do programa/projeto, eles estarão mais comprometidos com o seu sucesso.

As contribuições da participação para a melhoria da efetividade das intervenções desenvolvimentistas são, provavelmente, a mais documentadas na literatura. $\mathrm{O}$ estudo a seguir, dada sua abrangência e qualidade, deixa pouca dúvida sobre o relevante papel desempenhado pela participação dos beneficiários em potencializar os efeitos dos programas/projetos.

Narayan (1995) avaliou 121 projetos de fornecimento de água em zonas rurais implantados por diferentes agências em 49 países em desenvolvimento. Ela provou que a participação contribuiu significativamente para a efetividade das intervenções, aumentando o percentual da população-alvo atingida, a proporção de sistemas de fornecimento de água em boas condições e os benefícios econômicos e ambientais dos projetos. Adicionalmente, o envolvimento dos beneficiários ajudou a garantir eqüidade no acesso às facilidades instaladas. A autora destacou que somente um projeto altamente efetivo tinha baixo nível de participação, e nenhum daqueles altamente participativos era pouco efetivo. 
As contribuições da participação para melhor focalização dos benefícios dos programas/projetos nos mais pobres e para o aumento de sua cobertura estão, também, evidenciadas numa avaliação do Banco Mundial. Um estudo do "World Bank's Operations Evaluation Department" (The World Bank, 2002a) mostrou que projetos gerenciados pelas comunidades locais eram sensivelmente mais exitosos que aqueles administrados por outras instituições e concluiu que a participação, em nível local, ajudou a assegurar que os serviços básicos alcançassem os mais pobres.

O monitoramento e a avaliação dos stakeholders primários conduzem, também, para uma melhor focalização das intervenções desenvolvimentistas. $\mathrm{O}$ uso de avaliações participativas garantiu que somente comunidades pobres fossem apoiadas pelo "Social Recovery Project" (SRP) em Zâmbia (The World Bank, 1999). De fato, sua estratégia de autofocalização foi capaz de direcionar os benefícios do projeto para os mais carentes. Adicionalmente, processos participativos tendem a aumentar a eqüidade de gênero. The World Bank (2002a) destaca que estudos sobre comunidades rurais em Burkina Faso, Camarões e Quênia mostraram que controles mais eqüitativos por homens e mulheres sobre os insumos e sobre as rendas geradas incrementaram em um quinto a produção agrícola.

Adotar enfoque participativo nos programas/projetos ajuda a prover os produtos desejados pelos beneficiários. Somente projetos formulados localmente e que iam ao encontro das necessidades dos pobres eram elegíveis para acessar os recursos do fundo do SRP. Participação também influenciou, no estudo de caso de Sri Lanka (SSP), a criação de um processo de decisão no âmbito da agência de desenvolvimento mais sensível aos interesses e prioridades das pessoas.

Outra importante contribuição da participação é permitir o uso do conhecimento local. Kottak (citado por Karl, 2000) analisou 68 avaliações ex post de maneira a identificar as principais lições aprendidas relacionadas as variáveis socioculturais em projetos de desenvolvimento rural apoiados pelo Banco Mundial. Projetos que eram baseados em um adequado entendimento das condições sociais tiveram taxas de retorno econômico duas vezes maiores que aqueles socialmente incompatíveis. Isso destaca a importância do envolvimento dos beneficiários para providenciar informações sobre a realidade social.

Semelhantemente à contribuição de empoderamento dos beneficiários, o nível da participação afeta diferentemente a efetividade das intervenções desenvolvimentistas, como pode ser visto no trabalho de Narayan anteriormente citado e no caso da participação comunitária no "Public Works Projects" (PWP) na África do Sul (Hoddinott et al., 2001). Os autores mostraram que a participação de facto - em que as pessoas tinham controle sobre as decisões dos projetos - estava associada a 
melhores relações custo/efetividade e focalização. A participação de jure

- em que as pessoas tinham autoridade formal para decidir, mas na prática não o faziam - era, contrariamente, menos efetiva e não aumentou, por exemplo, a quantidade de oportunidades de emprego direcionadas às mulheres.

\section{Eficiência das estratégias}

Eficiência é a medida de produtividade do processo de implementação: quão racionalmente uma intervenção entrega os seus produtos e/ou serviços em termos de custo e tempo.

Participação aumenta a eficiência das estratégias de redução da pobreza pela redução dos custos associados à resolução de conflitos e desentendimentos. Métodos participativos bem conduzidos podem promover concordância, cooperação e interação entre os diversos stakeholders (Karl, 2000), diminuindo os custos de tempo e energia freqüentemente gastos pelos profissionais das agências de desenvolvimento para explicar ou convencer as pessoas envolvidas sobre os benefícios e as estratégias dos programas/projetos.

Participação, também, otimiza a divisão do trabalho e ajuda na formação de um "pool" de recursos locais. A mobilização de recursos financeiros e não-financeiros (trabalho, informação, contribuições em espécie) promovida pelo envolvimento dos beneficiários pode reduzir os custos de implementação dos programas/projetos (Michener, 1998). Participação é custo-eficiente, porque, se pessoas da localidade atendida estão assumindo responsabilidades nas atividades da intervenção, menos recursos externos serão requeridos e os profissionais contratados pelas agências de desenvolvimentos estarão menos envolvidos em questões operacionais.

Experiências práticas têm mostrado que os retornos dos investimentos realizados em estratégias participativas são altos. Na Costa do Marfim, um enfoque participativo reduziu os custos de manutenção do "National Rural Water-Supply Programme" em 50\% (Bhatnagar e Williams, 1992). Na mesma linha, Uphoff (1992) encontrou que a relação custo/benefício dos componentes participativos de projetos de irrigação nas Filipinas e no Sri Lanka tinha taxas positivas de 1,5, bem acima da média dos demais. Além disto, uma avaliação específica dos projetos de Sri Lanka apontou uma taxa interna de retorno de $24 \%$. Segundo o autor, aproximadamente metade dos benefícios dos projetos poderiam ser atribuídos aos seus componentes participativos, que demandavam menos que $10 \%$ dos custos totais das intervenções. Igualmente, os projetos de infra-estrutura dos PAPR foram $40 \%$ mais baratos, quando implementados pelas comunidades. 


\section{Sustentabilidade das estratégias}

Sustentabilidade também é um termo de sentido amplo e com diversas interpretações para diferentes situações. No contexto deste estudo, está sendo utilizado o conceito de sustentabilidade de projeto, i.e., a extensão em que os stakeholders primários de uma intervenção desenvolvimentista continuarão a perseguir seus objetivos após o encerramento da implementação do programa/projeto pela agência de desenvolvimento.

A contribuição da participação para aumentar a sustentabilidade das estratégias de redução da pobreza pode ser indiretamente demonstrada pelo desempenho precário de programas/projetos não-participativos. Estes tendem a ter custos mais altos. Tais custos incluem a não utilização da estrutura física criada e a sua manutenção deficiente. Por exemplo, embora o "Kampung Improvement Program" na Indonésia tenha obtido sucesso na construção da infra-estrutura física, algumas facilidades não eram utilizadas e outras estavam quebradas devido a sua péssima manutenção. Estes problemas foram atribuídos, em parte, ao baixo nível de envolvimento dos stakeholders primários na implantação do programa, levando a inexistência de um sentimento de "propriedade" local. (Bhatnagar e William, 1992)

Descobertas semelhantes foram feitas por Cernea (citado por Karl, 2000), que analisou 25 projetos financiados pelo Banco Mundial para medir sua sustentabilidade. De acordo com o autor, 13 destes projetos foram considerados não-sustentáveis. Embora a razão primária deste problema tenha sido insuficiência de recursos, o não-envolvimento dos stakeholders primários na formulação e implementação dos projetos foi identificado como fator importante para este insucesso.

Os casos seguintes mostram que participação pode garantir a "propriedade" local e responsabilização pela manutenção das estruturas criadas pelas intervenções desenvolvimentistas, incrementando a durabilidade dos seus benefícios.

Coirolo e Barbosa (2002) informam que cerca de $90 \%$ dos projetos que receberam financiamento dos PAPR de 1995 a 1997 continuam funcionando atualmente.

Um estudo de Ninan (1998) avaliou quatro projetos de irrigação na Índia financiados por doadores europeus. Ele mostrou que a participação comunitária, particularmente das mulheres, resultou na formação de comitês locais que promoveram um grande senso de envolvimento das pessoas. Todos os comitês comprometeram-se a manter as estruturas criadas e a realizar outras atividades após o encerramento dos projetos. 
Katz e Sara (s.d.) conduziram um estudo sobre fornecimento de água em 1.875 domicílios em áreas rurais de comunidades carentes em 6 países (Benin, Bolívia, Honduras, Indonésia, Paquistão e Uganda). Eles descobriram que a sustentabilidade dos projetos é maior quando os stakeholders primários (neste caso, os membros das famílias) escolhem o tipo de sistema a ser construído e o nível do serviço que eles preferem. Interessantemente, a sustentabilidade era ainda maior quando a demanda era expressa diretamente pelos beneficiários, ao invés de sê-la via líderes locais ou representantes. Essa participação direta leva a um alto senso de "propriedade" local e promove maior disposição para pagar pela manutenção dos serviços.

As diferentes contribuições da participação para a sustentabilidade, fruto dos diferentes níveis de envolvimento dos beneficiários, são confirmadas em outros estudos. Na primeira fase do SSP, como os agricultores não eram consultados sobre a escolha dos locais de instalação dos tanques de água, a manutenção da estrutura era negligenciada. Contrariamente, na segunda fase do programa, com o aumento da participação dos agricultores, a sustentabilidade foi incrementada, com organizações locais estabelecendo ligação direta com os serviços de extensão rural e de crédito agrícola, responsabilizando-se pela manutenção da infra-estrutura criada.

De igual forma, o alto nível de participação dos beneficiários aumentou o senso de "propriedade" local da infra-estrutura criada pelo SRP. Os benefícios do projeto tornaram-se sustentáveis pela melhoria da capacidade de gerenciamento das comunidades (devido a sua participação na fase de implementação) e pelo treinamento dos profissionais do projeto e de membros da comunidade.

Participação aumenta as chances de os programas/projetos serem sustentáveis, porque os beneficiários, quando envolvidos, estão mais dispostos a manter as suas atividades, mesmo com a cessação dos recursos externos, e são mais aptas a fazê-lo, dado que a própria participação ajuda as pessoas a desenvolverem as habilidades necessárias (Karl, 2000).

A presente seção tem tentado responder algumas questões relacionadas com a ligação entre participação e redução da pobreza. Aliteratura sugere que o envolvimento dos beneficiários aumente o impacto das estratégias de redução da pobreza por intermédio do empoderamento dos stakeholders primários e do aumento da efetividade, da eficiência e da sustentabilidade das intervenções desenvolvimentistas. Essas contribuições são inter-relacionadas e reinforçam-se sinergeticamente.

Participação melhora a qualidade de vida dos pobres pela promoção de sua independência e autoconfiança e pelo aumento de suas capacidades, permitindo-lhes perseguir estratégias de sobrevivência mais sustentáveis. Quando empoderadas, as pessoas têm seus talentos e 
potenciais expandidos, sendo capazes de entender seus problemas e tomar atitudes para resolvê-los, de mobilizar novos recursos e de influenciar ou negociar em melhores condições com instituições de crédito, com empregados e dirigentes de órgãos públicos e de agências de desenvolvimento, com lideranças locais, entre outros. Participação constrói, também, uma rede de proteção social para o pobre, que amortece os efeitos de choques adversos e impede que ele se aprofunde na miséria.

Participação ajuda a focalizar os benefícios das intervenções desenvolvimentistas nos mais pobres. O envolvimento dos stakeholders primários no planejamento, implementação, monitoramento e avaliação de políticas, programas e projetos direciona os seus produtos e serviços para os mais carentes e vulneráveis, evitando que sejam capturados pelos não-pobres e/ou pelas elites locais. Além disso, leva a uma mais equiitativa distribuição dos seus benefícios, porque impõe às agências de desenvolvimento a disponibilização de informações sobre os objetivos e recursos de seus programas/projetos, permitindo aos stakeholders primários controlar e supervisionar as suas atividades.

Participação racionaliza o uso dos recursos e reduz os custos operacionais dos programas/projetos por meio das contribuições em espécie, do trabalho e outros insumos dos stakeholders primários, permitindo às agências de desenvolvimento aumentar a quantidade e qualidade de suas intervenções, maximizando os benefícios para os pobres. Ademais, a mobilização de recursos endógenos cria incentivo positivo para a "propriedade" local e para a responsabilização, aumentando a sustentabilidade dos projetos e, dessa forma, fazendo com que os pobres beneficiem-se por mais tempo das facilidades criadas.

Os estudos de caso apresentados neste trabalho permitem ao autor afirmar, também, que diferentes níveis de participação proporcionam diferentes contribuições para a redução da pobreza. Baixos níveis de envolvimento dos beneficiários - como no "Water Supply Project" na Tanzânia, na primeira fase do "Self-Help Support Programme" em Sri Lanka e na participação de jure na África do Sul - causam menores impactos sobre os resultados dos programas/projetos que altos níveis de participação - como no caso ganense, no "Mvula Trust Programme", nos "Projetos de Alívio da Pobreza Rural", na segunda fase do "Self-Help Support Programme", no "Social Recovery Project" e na participação de facto na África do Sul. Um enfoque participativo que promova o envolvimento dos stakeholders primários no processo de decisão e melhore sua capacidade de automobilização tende a aumentar o impacto das estratégias de redução da pobreza, porque tornam os pobres mais capazes, informados, confiantes e pró-ativos para tomar iniciativas que resolvam os seus problemas. 


\section{Desafios e dificuldades para a participação}

$\mathrm{Na}$ seção anterior, pôde ser visto que o envolvimento dos stakeholders primários nas atividades dos programas/projetos aumenta a probabilidade de as estratégias de redução da pobreza atingirem seus objetivos. Dessa forma, se participação contribui para incrementar os impactos das intervenções, por que todas as agências de desenvolvimento não adotam processos participativos? Porque a participação dos beneficiários é um processo complicado e que não tem fórmula ideal. Ela sofre de dificuldades de ordem econômica, social, de tempo e de recursos e apresenta desafios de natureza pessoal, local, organizacional e comportamental (Chambers, 1993; Chambers, 1994; Leurs, 1996). Particularmente, uma participação "real" ou de alto nível (i.e., o envolvimento dos stakeholders primários no processo de decisão e a melhoria de sua capacidade de automobilização) requer um contexto socioeconômico adequado.

Além disso, direta e intensiva participação dos beneficiários nem sempre é apropriada (The World Bank, 2002a). É importante ter clareza sobre os objetivos e valores adicionados ao processo, já que os custos de oportunidade para os envolvidos podem ser altos. Em alguns casos, a participação pode restringir-se a apenas uma consulta às pessoas sobre as suas prioridades e interesses.

Esta seção identifica os principais desafios e dificuldades para garantir uma "real" participação e sugere as mudanças necessárias.

\section{Empoderamento dos beneficiários}

Empoderamento é agora um objetivo importante da maioria das intervenções desenvolvimentistas. Contudo, deve ser enfatizado que empoderamento, especialmente de pessoas pobres, permanece um ideal mais que uma realidade nos programas e projetos (Eyben e Ladbury, 1995). O estudo "Voices of the Poor", conduzido em 60 países, mostra que uma característica comum da vida dos pobres é, ainda, um sentimento de ausência de poder e de voz, apesar dos esforços de empoderamento conduzidos nas últimas décadas pelas agências de desenvolvimento (The World Bank, 2002a). O principal desafio para as agências é aprofundar o entendimento dos termos "participação" e "empoderamento", reconhecendo suas complexidades, fortalezas e limitações (Oakley e Clayton, 2000; Cleaver, 1998). Os próximos três estudos de caso destacam essa questão.

Michener (1998) analisou o uso da participação em um projeto de educação não-formal em Burkina $\mathrm{Faso}^{10}$. Ela fez importante observação sobre as estratégias participativas: há freqüentemente conflito entre as noções de participação e de empoderamento entre os diferentes 
stakeholders, e esse problema é indicativo da dubiedade dos conceitos. Nesse caso, os profissionais de campo do projeto não estavam convencidos da retórica de empoderamento da "participação". Eles não acreditavam que as comunidades eram capazes de assumir papel relevante em seu próprio desenvolvimento. Para eles, "participação" era apenas uma formalidade. As perspectivas dos beneficiários também eram modeladas pelas suas experiências anteriores com as agências de desenvolvimento. Para eles, participação tinha pouco a ver com independência e empoderamento. Em vez disso, era uma oportunidade para extrair recursos das agências.

Semelhantemente, Matthäus (s.d.), analisando o Projeto "Prorenda Urbano e Regional” em Pernambuco, que apóia processos de desenvolvimento local sustentável, encontrou que, em alguns municípios, é muito difícil mobilizar os beneficiários. Existe um forte sentimento que cabe ao Poder Público fazer tudo e, portanto, eles não devem se envolver.

Botchway (2001) examinou a noção de participação como base para o empoderamento no contexto de um projeto de desenvolvimento rural financiado pelos governos canadense e ganense chamado "Northern Regional Rural Integrated Program" (Norrip). O método participativo do Norrip não permitiu às pessoas definirem suas necessidades prioritárias e, desta forma, elas não foram empoderadas. De fato, as comunidades entraram em uma nova forma de dependência, em que precisavam de forças externas para manter o sistema de abastecimento de água ${ }^{11}$. O autor concluiu que o discurso da participação e do empoderamento seria uma nova ideologia em que as pessoas não decidem o que é relevante para elas, mas apenas envolvem-se nas atividades dos programas/projetos sem mudar as condições socioeconômicas, sob as quais elas têm de desenvolver-se.

Esses estudos exemplificam a dificuldade de realizar os objetivos de quebrar a mentalidade de dependência dos pobres e aumentar o controle sobre suas vidas. Além disso, empoderamento implica não somente construir novas capacidades, mas também dar condições de empregar os novos conhecimentos e habilidades de forma produtiva. $\mathrm{O}$ caso camaronês a seguir destaca a necessidade de mudar as relações sociais tradicionais de maneira a permitir o empoderamento dos beneficiários.

Mayoux (2001) analisou a experiência de sete programas participativos de microcrédito na República dos Camarões em promover o empoderamento das mulheres. A autora identificou que a capacidade das mulheres, para usar os créditos concedidos, era seriamente limitada por relações hierárquicas no interior das famílias e dos grupos. Ela concluiu que, ao menos que os programas movam-se de uma visão complacente sobre o poder da participação, eles podem tornar-se apenas mais uma forma cínica de auto-ajuda, em que os custos do desenvolvimento recaem sobre as mulheres. 
Diversas limitações para o empoderamento apresentam-se quando

os recursos materiais são insuficientes. Osmani (2000) sugere que melhorar concomitantemente a situação econômica do pobre deva ser parte integral dos esforços de empoderamento, haja vista que um grupo de pessoas em situação de insegurança dificilmente será exitoso numa barganha com grupos mais poderosos. Além disso, é necessário reconhecer as dificuldades que os pobres enfrentam para sobreviver, e que a capacidade das pessoas para autodesenvolvimento é limitada, variável e altamente dependente de fatores externos (Cleaver, 1998). As necessidades econômicas dos pobres são enormes, e assumir que eles poderão vencer esta situação sozinhos é ingenuidade.

Um importante desafio organizacional para o empoderamento dos beneficiários de estratégias de redução da pobreza é a tendência de as agências de desenvolvimento e os doadores em limitar a participação a apenas aspectos operacionais, evitando transferir poder sobre o gerenciamento dos recursos para os stakeholders primários. Por exemplo, Weiss (s.d.), estudando a experiência comparada com fundos socioambientais na Amazônia, no Brasil e no Exterior, achou que as pressões de doadores para manter o controle sobre os recursos limitam a capacidade de a comunidade ajudarem-se e de obter financiamento para seus projetos.

\section{Efetividade da estratégia}

Direcionar os esforços desenvolvimentistas para ir ao encontro das necessidades dos mais pobres é uma das mais importantes contribuições da participação. Contudo, há desafios práticos para implementar enfoques participativos efetivos, como pode ser visto no caso do "North Western Province Dry Zone Participatory Development Project" (DZP) no Sri Lanka (Kar e Backhaus, 1994). De acordo com os autores, o problema é que, sendo baseado num planejamento participativo, mas, por outro lado, tendo de trabalhar com um conjunto pré-estabelecido de atividades e objetivos, o DZP inevitavelmente caía em contradição quando as prioridades dos membros das comunidades não coincidiam com o catálogo de serviços disponíveis do Projeto. Assim, os esforços para promover a participação dos beneficiários eram parcialmente desperdiçados.

Uma outra dificuldade para a focalização dos benefícios das intervenções desenvolvimentistas é a tendência dos métodos participativos de misturarem os conceitos de "comunidade" e "público-alvo". Erroneamente assume-se que a "comunidade" ou o "grupo" é facilmente identificado, apesar das consideráveis evidências sobre a subjetiva e mutável natureza de sua composição (Cleaver, 1998). 


\section{Eficiência das estratégias}

Embora a participação dos beneficiários possa racionalizar o uso dos recursos dos programas/projetos, ela tende, em algumas situações, a aumentar os custos operacionais e de transação das intervenções desenvolvimentistas.

Esses custos adicionais da participação têm sido amplamente apontados na literatura. Bhatnagar e Williams (citado por Karl, 2000), em um estudo do Banco Mundial, identificaram que projetos participativos frequientemente requerem um maior esforço de planejamento do que os não-participativos. Mais tempo também é necessário para os processos de identificação e de consulta dos grupos e organizações que devem ser envolvidas, para alcançar a concordância dos diferentes stakeholders e para construir uma confiança mútua.

Karl (2000), numa pesquisa do Banco Mundial, igualmente encontrou que participação aumenta o orçamento da intervenção: projetos participativos gastam de $10 \%$ a $15 \%$ a mais para pagar o seu pessoal e outros envolvidos. Deste valor, 2/3 são para a inclusão de especialistas em técnicas participativas. Adicionalmente, esses projetos exigem uma supervisão mais intensa durante as primeiras etapas de implementação: 27 semanas, em média, contra 17 de projetos não-participativos.

Além de aumentar as despesas de implementação dos programas/ projetos, participação impõe custos de oportunidades aos envolvidos. Ela demanda tempo e energia dos stakeholders primários (Michener, 1998). Esses custos podem ser particularmente altos para as mulheres e grupos marginalizados. As pessoas pobres, normalmente, não têm disponibilidade para participar de reuniões, especialmente quando isso as obriga a afastarse da produção (Karl, 2000).

Participação tem-se tornado uma demanda pesada para os stakeholders primários (Michener, 1998). Argumentos para justificar o custo-eficiência da participação têm-se defrontado com acusações que essa eficiência resulta na destinação menor de recursos por parte das agências e dos doadores, com a transferência dos custos operacionais para os beneficiários (Oakley, 1991).

Um outro significativo custo da participação é a capacitação específica que ela demanda. Processos participativos requerem que todos os stakeholders, desde os beneficiários até os diretores das agências de desenvolvimento, sejam devidamente treinados. Particularmente, os profissionais das agências devem ser capacitados em técnicas participativas, e facilitadores habilitados devem ser identificados e contratados (Karl, 2000). 


\section{Sustentabilidade das estratégias}

De acordo com o relatório do Banco Mundial sobre o SRP, participação da comunidade e "propriedade" local são pré-condições para a manutenção da infra-estrutura física criada pelos projetos, porém elas de per si não garantem sustentabilidade. $\mathrm{O}$ documento destaca que não somente os beneficiários têm que ser envolvidos, mas novos papéis e responsabilidades têm que ser assumidos. Além disso, é necessário providenciar conhecimento técnico e recursos financeiros, para que a manutenção possa ser efetuada.

Esta seção identificou os principais desafios e dificuldades para implementar estratégias participativas. Eles foram agrupados em termos de empoderamento, efetividade, eficiência e sustentabilidade.

Empoderamento requer uma "real" participação dos stakeholders primários nas decisões e atividades determinantes das intervenções desenvolvimentistas. Contudo, os mecanismos de empoderamento são complexos e dependentes de recursos externos. Os beneficiários necessitam ganhar novas habilidades, capacidades, direitos e responsabilidades. Isso demanda mudanças em todos os níveis. Organizações públicas e privadas e agências de desenvolvimento devem criar um ambiente propício e providenciar oportunidades para a participação.

A efetividade das estratégias participativas é limitada pelo modus operandi das agências de desenvolvimento e pelos organismos doadores. Eles tendem a ser burocráticos, a impor objetivos "de cima para baixo" e a definir orçamentos rígidos, o que impede uma "real" participação. Ademais, uma visão do público-alvo como uma comunidade homogênea e unida atrapalha uma melhor focalização e cobertura.

Como participação demanda um maior desenvolvimento dos recursos humanos, mais tempo e treinamento que enfoques não-participativos, estes custos adicionais podem reduzir as vantagens de custo-eficiência das intervenções participativas.

Sustentabilidade requer "propriedade" local dos programas/projetos. Dessa forma, os beneficiários são desafiados a assumir novos papéis e responsabilidades, demandando capacitação específica e uma problemática e, algumas vezes, conflituosa redistribuição de poder e recursos entre os diferentes stakeholders.

Muitos desses desafios e dificuldades podem ser vencidos, mas alguns são mais difíceis de resolver. Participação irá permanecer limitada e insustentável, se não forem criadas as oportunidades e os mecanismos para o envolvimento dos stakeholders primários nos processos de decisão e de alocação de recursos, especialmente em nível local. Participação implica que a voz dos beneficiários seja fortalecida de maneira a influenciar os contextos socioeconômicos em que eles estão inseridos. Assim, faz-se 
necessário, primeiro, estabelecer instituições locais que sejam focadas nos mais pobres, sujeitas ao controle social, estáveis e flexíveis e, segundo, mudar as atitudes e comportamentos dos diversos stakeholders de maneira a permitir uma "real" participação. Adicionalmente, como participação envolve custos e benefícios, ela deve ser otimizada (i.e., um nível suficiente para atingir os resultados desejados), em vez de maximizada. Dessa forma, métodos participativos que sejam contexto-específicos, que tenham baixo custo operacional para as agências e alto retorno para os pobres, devem ser adotados.

\section{Conclusões e recomendações}

O tamanho e a complexidade do desafio de combater a pobreza têm criado a necessidade de se identificar novas maneiras de atacar o problema. O envolvimento dos beneficiários nas atividades das estratégias de redução da pobreza é parte de um inovador e poderoso enfoque para o desenvolvimento.

O presente estudo analisou as contribuições da participação para a redução da pobreza. Ele identificou que a participação aumenta o impacto das estratégias por meio do empoderamento dos beneficiários e pelo incremento da efetividade, da eficiência e da sustentabilidade das intervenções desenvolvimentistas. Desta maneira, participação melhora a qualidade de vida dos pobres, constrói sua rede de proteção social, ajuda a focar os benefícios dos programas/projetos para os mais carentes e aumenta a qualidade e quantidade das intervenções.

Evidências da literatura apontadas aqui confirmam essas contribuições. Mais importante, os estudos de caso indicam que uma participação "real" - aquela que envolve os stakeholders primários no processo de decisão e aumenta sua capacidade de auto-organização - potencializa os impactos das estratégias de redução da pobreza.

Contudo, garantir uma "real" participação dos beneficiários não é fácil e sem problemas. Particularmente, estratégias participativas são afetadas por dificuldades sociais, econômicas, de tempo e de recursos e existem desafios de ordem pessoal, local, organizacional e comportamental.

Considerando todos esses pontos, são apresentadas, a seguir, recomendações para futuras políticas. Estas sugestões podem ajudar a superar os desafios e dificuldades identificados e a maximizar as contribuições da participação dos beneficiários nas estratégias de redução da pobreza.

Primeiramente, dada a extensão da contribuição da participação para a redução da pobreza, conforme visto neste trabalho, a óbvia implicação para as políticas é que maiores investimentos devem ser feitos em estratégias participativas. Os stakeholders primários devem ser 
envolvidos em todas as fases dos programas/projetos: formulação, implementação, monitoramento e avaliação. As contribuições da participação não podem ser completamente realizadas quando ela está limitada a apenas um estágio em particular. Além disso, organizações públicas e privadas e agências de desenvolvimento devem oferecer oportunidades para a participação efetiva dos beneficiários nos processos de decisão e de alocação de recursos e devem apoiá-los nas suas iniciativas de autoorganização.

Em segundo lugar, os stakeholders primários devem ser capacitados para coletar e analisar informações, para realizar o diagnóstico dos problemas locais e identificar soluções, para negociar diferentes interesses e opiniões e para articular as partes envolvidas. Ademais, tempo suficiente deve ser dado para o treinamento em métodos participativos e para que os comportamentos e atitudes sejam adaptados. Como alertado por Levy (2000), para aprender, pensar, inovar e decidir em comum, é preciso tempo.

Terceiro, as agências de desenvolvimento devem ser flexíveis no desenho e implementação dos programas/projetos. Elas devem ser menos burocratizadas, adotar enfoque de aprendizagem organizacional, fortalecer os mecanismos de controle social e serem orientadas por demanda.

Quarto, as agências de desenvolvimento devem identificar e utilizar instituições locais que sejam mais sensíveis às demandas e necessidades dos pobres e abertas à participação dos beneficiários. Ao mesmo tempo, elas devem lutar contra instituições, redes e regras existentes que produzam exclusão e desigualdade social (Mayoux, 2001).

Quinto, as agências de desenvolvimento devem reconhecer que o seu público-alvo é formado por grupos de indivíduos heterogêneos, com diferentes e, em alguns casos, interesses antagônicos. A intervenção deve ser apropriada às necessidades dos grupos mais carentes, e um enfoque negocial deve ser adotado para solucionar os conflitos gerados (Leeuwis, 2000).

Sexto, as agências de desenvolvimento devem adotar métodos participativos que sejam apropriados ao contexto local e aos objetivos da intervenção, que não aumentem significativamente os custos operacionais dos programas/projetos e os custos de oportunidade dos envolvidos.

A adoção dessas recomendações e o desenvolvimento de novos enfoques participativos podem melhorar a situação dos pobres. Pobreza é um problema sério e complexo e sua redução dependerá de um grande e persistente esforço e da utilização de estratégias apropriadas. 
1 Para maior discussão sobre os conceitos e as causas da pobreza, ver Chambers (1983) e Alcock (1997).

2 Stakeholder é pessoa, grupo ou instituição que tem interesse em determinada política ou questão. Stakeholder primário é aquele que é diretamente, positiva ou negativamente, afetada pela política/questão. O stakeholder primário de uma estratégia de redução da pobreza, é o pobre. Stakeholder secundário é aquele afetado indiretamente pela política/ questão ou intermediário no processo. Para informações adicionais sobre análise de stakeholders, ver DFID (1995).

3 Estratégias de redução da pobreza são normalmente implementadas por meio de intervenções de desenvolvimento. Programas e projetos são as unidades básicas de planejamento e execução dessas intervenções.

4 As capacidades (ou capitais) habilitam as pessoas a usarem seus ativos de diferentes maneiras para aumentar o seu bem-estar. Capital humano envolve bons níveis de saúde e de educação. Capital social engloba um sentido de pertencimento a um grupo - e características como confiança, liderança, identidade - e valores que dão sentido a vida e ajudam a sua organização. Capital político inclui a capacidade de representar a si ou a outros, de ter acesso à informação e de poder influir na vida da comunidade ou do país. (The World Bank, 2002a).

5 Para maior discussão sobre as diferentes interpretações do termo "participação", ver Oakley (1991).

6 Hayes (2003) lista 30 diferentes mecanismos para envolver o público em geral. Cada um deles atende a uma situação específica, gerando certas contribuições.

7 Redução da pobreza é entendida neste estudo como o fenômeno multidimensional que envolve mudanças positivas na qualidade de vida, nas capacidades e nos direitos dos pobres.

8 Sobre os diferentes conceitos de empoderamento, ver Oakley e Clayton (2000).

9 Por efeito entende-se uma mudança tangível em relação à situação/problema inicial que pode ser atribuída à intervenção.

${ }^{10}$ Embora esta não seja uma estratégia de combate à pobreza, strictu sensu, o caso foi selecionado devido à relevância das questões apresentadas.

${ }^{11}$ Isto é o que Michener (1998) chama de "paradoxo do agente externo": dependência tem sido criada no processo de promover participação e independência.

\section{Referências bibliográficas}

Alcock, P. Understanding poverty. 2a. ed. Nova Iorque: Palgrave, 1997.

Barros, R.P., Henriques, R., Mendonça, R. A estabilidade inaceitável: Desigualdade e pobreza no Brasil. Texto para discussão no 800. Rio de Janeiro: IPEA, 2001.

Bhatnagar, B. e Williams, A.C. Participatory development and the World Bank: Potential directions for change. World Bank Discussion Paper n. 183. Washington: The World Bank, 1992. 
BLACKBURN, J. e Holland, J. Who changes? Institutionalizing Participation in development. Londres: ITP, 1998.

BoRTEI-DOKu, E. People's Participation Project: Ghana. In: Projects with people: The practice of participation in rural development. Peter Oakley (ed.). Geneva: International Labour Office, 1991

Bотсншау, K. Paradox of empowerment: Reflections on a case study from Northern Ghana. World development. Volume 29, n. 1, p. 135-153. Oxford: Elsevier Science Ltd., 2001.

Chambers, R. Rural development: Putting the last first. Londres: ITP, 1983.

. Challenging the professions: Frontiers for rural development. Londres:

ITP, 1993.

. Participatory Rural Appraisal (PRA): Challenges, Potentials and

Paradigm. World development. Volume 22, n. 10, p. 1437-1454. Oxford: Elsevier Science Ltd., 1994.

Cleaver, F. Paradoxes of participation: a critique of participatory approaches to development. Paper apresentado na Conferência 'Participation - The new tyranny?', University of Manchester. Material não publicado. 1998.

Coirolo, L. e Barbosa, T. Desenvolvimento rural e alívio da pobreza no Nordeste do Brasil. Em breve, n. 11, outubro 2002.

DFID. Stakeholder participation and analysis. Londres: Department for International Development, 1995.

EyBEn, R. e LADBURY, S. Popular participation in aid-assisted projects: Why more in theory than practice? In: Power and participatory development: theory and practice. Nici Nelson and Susan Wright (eds.). London: ITP, 1995.

Grootaert, C. Does social capital help the poor? A Synthesis of findings from the local level institutions studies in Bolivia, Burkina Faso and Indonesia. Local Level Institutions Working Paper n. 10. Washington: The World Bank, 2001.

HaYes, P. Mecanismos de Consulta. Subsidiando a Formulação de Políticas Públicas por Meio de Consultas. A Arte de Perguntar, Ouvir e Concluir o Processo. Traduzido do "Informing public policy through consultation. The art of asking, and listening and following through. Consultation mechanisms. Otawa, june 2003.

Hoddinott, J., Adato, M., Besley, T., Haddad, L. Participation and poverty reduction: Issues, theory, and new evidence from South Africa. FCND Discussion Paper n. 98. Washington: International Food Policy Research Institute, 2001.

KAR, K. and Backhaus, C. Old. Wine in new bottles? Experiences with the Application of PRA and Participatory Approaches in a Large-Scale, Foreign-Funded Government Development Programme in Sri Lanka. Material não publicado. 1994.

KARL, M. Monitoring and evaluating stakeholder. Participation in agriculture and rural development projects: a Literature Review. 2000. www.fao.org/sd/Ppdirect/Ppre0074.htm

KATZ, T. e SARA, J. Making rural water supply sustainable: Recommendations from a global study. UNDP-World Bank Water and Sanitation Program. www.wsp.org/pdfs/ global_ruralstudy.pdf

LeEuwIS, C. Reconceptualizing Participation for Sustainable Rural Development: Towards a Negotiation Approach. Development and Change. Volume 31, p. 931-959. Oxford: Blackwell Publishers, 2000.

LEURS, R. Current challenges facing participatory rural appraisal. Public administration and development. Volume 16, pp. 57-72. Londres: John Wiley \& Sons, Ltd., 1996.

Levy, P. A inteligência coletiva: por uma antropologia do ciberespaço. $3^{a}$ edição. São Paulo: Edições Loyola, 2000. 
MatthäUs, H. Apoio a processos de desenvolvimento local sustentável: o Projeto Prorenda Urbano e Regional/PE. www.femica.org.gt/documentos/base_documental/VIIRED/ horst_mattaus $2 . h t m$

Mayoux, L. Tackling the down side: Social capital, women's empowerment and microfinance in Cameroon. Development and Change. Volume 32, pp. 435-464. Oxford: Blackwell Publishers, 2001.

MichenER, V.J. The participatory approach: Contradiction and co-option in Burkina Faso. World Development. Volume 26, n. 12, pp. 2105-2118. Oxford: Elsevier Science Ltd, 1998. NARAYAN, D. The contribution of people's participation: evidence from 121 Rural Water Supply Projects. Environmentally Sustainable Development Occasional Paper Series n. 1. Washington: The World Bank, 1995.

Nelson, N. e Wright, S. Participation and Power. In: Power and Participatory Development: Theory and Practice. Nici Nelson and Susan Wright (eds.). Londres: ITP, 1995.

NinAN, K.N. An Assessment of European-aided Watershed Development Projects in India from the Perspective of Poverty Reduction and the Poor. CDR Working Paper 98.3. Copenhagem: CDR, 1998.

OAKLey, P. Projects with people: the Practice of Participation in Rural Development. Geneva: International Labour Office, 1991.

OAKley, P. e Clayton, A. The monitoring and evaluation of empowerment: a Resource Document. Oxford: INTRAC, 2000.

Oakley, P., Pratt, B., Clayton, A. Outcomes and Impact: Evaluating Change in Social Development. INTRAC NGO Management and Policy Series n. 6. Oxford: INTRAC, 1998.

Osmani, S.R. Participatory Governance, People's Empowerment and Poverty Reduction. UNDP/SEPED Conference Paper Series n. 7. 2000. www.undp.org/seped/publications/ empower_pov_red.pdf

Rudqvist, A. e Woodford-Berger, P. Evaluation and Participation: Some Lessons. SIDA Studies in Evaluation 96/1. Estocomo: SIDA, 1996.

SAmaranayake, M. Introducing Participatory Learning Approaches in the Self-help Support Programme, Sri Lanka. In: Who Changes? Institutionalizing Participation in Development. James Blackburn and Jeremy Holland (eds.). Londres: ITP, 1998.

Therkildsen, O. The Desirable and the Possible: Participation in a Water Supply Project in the United Republic of Tanzania. In: Projects With People: The Practice of Participation in Rural Development. Peter Oakley (ed.). Geneva: International Labour Office, 1991.

The World Bank. Zambia: The Social Recovery Project's Community Initiatives Component. Africa Region Findings n. 137. 1999. www.worldbank.org/afr/findings/english/ find137.htm

World Development Report 2000/2001: Attacking Poverty. Nova Iorque: Oxford University Press, 2001.

. Empowerment and Poverty Reduction: a Sourcebook. 2002a. www.worldbank.org/poverty/empowerment/sourcebook/draft.pdf

. Community Driven Development Case Study: Mvula Trust. 2002b.

wbln0018.worldbank.org/essd/CDDWk2000.nsf/9a0da286b06474fe852569f30061c879/ 7c1e339e4f2661f685256a480065bed6?OpenDocument

Uphoff, N. Monitoring and Evaluating Popular Participation in World Bank-Assisted Projects. In: Participatory Development and the World Bank: Potential Directions for Change. World Bank Discussion Paper n. 183. Bhuvan Bhatnagar and Aubrey C. Williams (eds.). Washington: The World Bank, 1992.

WeIss, J.S. Experiência Comparada com Fundos Socioambientais na Amazônia, no Brasil e no Exterior. www.nepam.unicamp.br/ecoeco/artigos/iv_en/plenaria/3.pdf 


\section{A participação dos beneficiários em estratégias de redução da pobreza: análise de suas contribuições}

Willber da Rocha Severo

O tamanho e a complexidade do desafio de combater a pobreza têm criado a necessidade de se identificar novas maneiras de atacar o problema. Um importante elemento da atual discussão é o envolvimento dos stakeholders primários nas atividades da intervenção de desenvolvimento.

O presente trabalho revisa e sintetiza a literatura especializada para analisar as contribuições da participação para a redução da pobreza. Ele identificou que participação aumenta o impacto das estratégias de redução da pobreza, por meio do empoderamento dos stakeholders primários e de melhorias na efetividade, na eficiência e na sustentabilidade das intervenções. Os estudos de caso indicam, também, que altos níveis de participação tendem a contribuir mais para o sucesso da estratégia. Contudo, garantir uma "real" participação dos beneficiários não é fácil.

Como resultado desse estudo, são dadas algumas recomendações para futuras políticas de combate à pobreza. Se adotadas, elas podem ajudar a vencer as dificuldades e desafios apontados e a maximizar as contribuições da participação.

\section{La participación del público beneficiario en estrategias de reducción de la pobreza: Análisis de sus contribuiciones \\ Willber da Rocha Severo}

El tamaño y la complejidad del desafío de combatir la pobreza, ha creado la necesidad de identificar nuevas formas de atacar el problema. Un importante elemento de la discusión actual es el involucramiento de todos los stakeholders primarios en las actividades de las intervenciones de desarrollo.

Este trabajo revisa y sistematiza bibliografía especializada, para analizar las contribuiciones de la participación en la reducción de la pobreza. El autor identificó que la partipación aumenta el impacto de las estrategias de reducción de la pobreza, mediante el empoderamiento de los stakeholders primarios y el aumento en la efectividade, la eficiencia y en la sustentabilidad de las intervenciones. Los estudios de caso indican, también, que altos niveles de participación tienen la tendencia de contribuir más con el éxito de la estrategia. A pesar de ello, garantizar una "real" participación del público beneficiario no es facil.

Como resultados del estudio, el autor da algunas recomendaciones para futuras políticas de combate a la pobreza. Implementándolas, ellas pueden contribuir a vencer obstáculos y desafíos señalados y a maximizar las contribuiciones de la participación.

\section{The participation of beneficiaries in strategies to reduce poverty: an analysis of their contributions \\ Willber da Rocha Severo}

The size and complexity of the challenge of fighting poverty have created the need to identify new ways to attack the problem. An important element of the present discussion is the involvement of primary stakeholders in intervention and development activities.

The present paper revises and synthesises specialized literature in order to analyse the contributions of participation to reduce poverty. It has identified that participation increases the impact of poverty reduction strategies by empowering primary stakeholders and by
Revista do

Serviço

Público

Ano 55

Números 1 e 2

Jan-Jun 2004

Willber da

Rocha Severo é especialista em Políticas Públicas e

Gestão

Governamental

e Coordenador-

Geral de

Parcerias

Empresariais do

Ministério do

Trabalho e

Emprego.

Contato:

willber.severo@ mte.gov.br 
improving effectiveness, efficiency, and the sustainability of interventions. Case studies also indicate that high levels of participation tend to contribute more to the success of the strategy. However, ensuring "real" beneficiary participation is not easy.

As a result of this study, some recommendations are given for future poverty fighting policies. If they are adopted, they can help overcome indicated difficulties and challenges and maximize participation contributions. 